\title{
Building up Open-Ended Empirical Modules in Translating: A Case Study of "Logical Meaning Extensions"
}

\author{
Wei Deng ${ }^{1} \&$ Lisha Zeng ${ }^{2}$ \\ ${ }^{1}$ School of Foreign Languages, Guangdong University of Finance, Guangzhou, China \\ ${ }^{2}$ Centre for Translation Studies, Guangdong University of Foreign Studies, Guangzhou, China \\ Correspondence: Lisha Zeng, Centre for Translation Studies, Guangdong University of Foreign Studies, \\ Guangzhou, China. E-mail: 1sz.20009@163.com
}

Received: October 17, $2020 \quad$ Accepted: December 14, $2020 \quad$ Online Published: December 22, 2020
doi:10.5539/ijel.v11n1p234 URL: https://doi.org/10.5539/ijel.v11n1p234

\begin{abstract}
This paper brings in the idea of building up "Open-ended Empirical Modules" (OEEMs) as a translation skill supported by the theory of contextual parameters. With examples being subcategorized into over twenty empirical rules, the study constructs an open-ended module of Logical Meaning Extensions (LME) as a representative paradigm and presents the know-how and know-why expertise. It is methodologically notable that the case analysis and demonstration of meaning extensions from concepts in SL to those in TL are conducted in a procedural way in which the cognitive mechanism of inferential processes of LME is verifiably explored. The significance of this research is seen in its display of a systematic way of generalization and classification of empirical rules for translation skills in teaching and learning translation. It may also provide translators with a possible method to follow in generalizing empirical rules from their own practice to enrich translating skills.
\end{abstract}

Keywords: open-ended empirical modules, logical meaning extensions, translation skills, modularity, teaching translation

\section{Introduction}

In the past decades, Translation Studies have developed significantly and the study into translation practice have also moved greatly forward. "Since the 1970s, Translation Studies have embraced skills and competences for the mapping of translation as a complex and specialised type of knowledge" (Calvo, 2011, p. 5). While PACTE $(2003,2015)$ refers translation competence as the underlying system of knowledge, skills and attitudes required to be able to translate, knowledge of translation skills has attracted a lot of attention. However, it is also notable that more often than not, translation skills such as amplification, addition, delexicalization, extension are generalized on the basis of relatively isolated cases without providing systematic solutions to complex translation problems in different contexts. For a long period in its history, traditional study of translation practice has often followed a research route featuring "phenomenon-perception $\rightarrow$ problem-identification $\rightarrow$ perspective application $\rightarrow$ features-analysis $\rightarrow$ skill/strategies-generalization" (cf. Fang, 2017; Zeng, 2012a). Just as Jakobsen (1993, p. 155) pointed out, "translations have often been highly valued, but the skill that produced them has not been held in high esteem". The limitations can be summarized from three aspects: 1) Translation skills in some researches are generally summarized from very limited examples without concrete concepts or terms to specify subcategorized empirical rules for manipulation of the skills concerned; 2) In most cases, discussion of the features of skills is short of theory-supported analysis of the workable technicality applied in different contexts or as Calvo (2011, p. 6) stated, "[some studies] aimed at tackling specific situations with no intention of achieving universal, theoretical validity".3) Presentation of translation skills in textbooks is rather weak in meeting scientific requirements such as being demonstratively descriptive and inferentially verifiable. Translation skills are generally problem-oriented, and translation problems, as defined by Nord $(1991$, p. 151) is "an objective problem which every translator (irrespective of his level of competence and the technical conditions of his work) has to solve during a particular translation task", should be addressed by systematic translation skills illustrated with workable and inferential procedures.

When taking the above-mentioned aspects into consideration, researchers may have to answer this question: How to make a translation skill widely-workable and being methodologically and theoretically significant? In this paper, we bring in the idea of building up "Open-ended Empirical Modules" (hereinafter as OEEM, which 
will be further explained in Section 3) so as to enrich the domain of translation skills. Here, we define an OEEM in translating studies as follows:

Working definition: An OEEM refers to a systematically and logically categorized set of open-ended empirical rules which are inductively generalized with specific concepts or terms for guiding the manipulation of problem-oriented translation practice.

Auxiliary definition: A skill-based OEEM, built up on the basis of large-scale corpus and big data, consists of subcategorized empirical rules that provide comprehensive solutions to complicated problems in different contexts and it attaches great importance to verifiable demonstration of the motivations and mechanism of how and why the skill is carried out to show a range of predictable regularity in problem-oriented translation practice.

Zeng (2012b, p. 1) points out that an OEEM is embodied as a unity of generalized empirical rules or methods featuring epistemology and methodology and it is expected to provide manipulatable rules and flexible choices for translation teachers and learners in dealing with translation problems. To make an in-depth elaboration of constructing OEEMs, the present research takes "logical meaning extension" as a representative paradigm.

\section{The Features of Logical Meaning Extensions}

Word meaning is a frequently-discussed concept (e.g., Austin, 1962; Clark \& Gerrig, 1983; Chandler, 1995; Galántai, 2002; Fawcett, 2007; Vahid Dastjerdi, 2011; Vitello \& Rodd, 2015; Armstrong \& Plaut, 2016; Jurko, 2017; Borghesani, 2019; Ke, 2019; Butler, 2020; Chen, 2020; Rodd, 2020) and perception of lexical meaning and choices of words with justified motivations is always a major and important task in the study of translating practice of moving the meaning of Source Language (SL) to Target Language (TL). But just as Baker (1992) noted, "it is rarely possible to analyze a word, ... into distinct components of meaning as language is much more complex to allow that", the complexity of making justifiable choices of words in bilingual translation involves different factors influencing language usages (cf., Duffy et al., 1988; Grace, 1998; Bolger et al., 2008; Yeibo, 2011; Chang, 2018 etc.). To explain the selecting process of word meaning is more complicated than many have thought, but what is even more frustrating for researchers in translation studies is to make the explanation in an inferential way, let alone to reveal the essence of meaning construction and the justification of selecting meaning components with a set of theoretic concepts.

Logic, as "the systematic evaluation of arguments for internal cogency" (Smith, 2003, p. 1), demonstrates the essential relations with regularity between things and phenomena of objective reality as well as between thoughts and ideas in human thinking and reasoning (Duc, 2005). Extension, as recognized as "thought of as recognition achieved at the cost of invoking a schematized version of the categorizing structure, one whose coarser-grained specifications are satisfied by the target" (Langacker, 2000, p. 102), is a basic characteristic of word meaning. Meaning can be extended "when a target is within an acceptable degree of strain recognized as matching the instance of prototypical meaning" (Kanasugi, 2019). In translation from SL to TL, logical meaning extension (hereinafter as LME), in this sense, relies on the translator's multidimensional perception and identification of the relevant contextual parameters including linguistic and cultural ones. Theoretically, exploration of inferential demonstration of the cognitive thinking process of LME requires concrete concepts or terms to reveal how the meaning extensions are reasonably realized. For instance, the meaning of a word, that is a concept, consists of two structural elements: connotative meaning (distinctive features) and denotative meaning (category of a referent). The former normally changes with context while the latter is relatively unchangeable. This essential feature in language uses is very important in teaching translation practice, for a word's meaning changing with contexts means that the word changes into another one with new connotative components given or constrained by its relevant contextual parameters and what is relevant to the word in SL is its denotative meaning (Zeng, 2002). Logically speaking, when the conceptual meaning of word A in SL is extended to that of word B in TL in terms of new context, parameters must retain part of its original semantic component(s) which is/are cognitively or logically compatible between the two concepts, and the conceptual relation between them can be qualitatively defined such as general-specific concepts, genus-specie concepts, collective-non-collective concepts, substance-emotion concepts, part-whole concepts, etc.

The effectiveness of generalization of LME, therefore, requires a systematic demonstration of thinking patterns in describing translating process which definitely deserves researchers' attention. It is academically significant to explore the thinking operations and inferential mechanism based on which an OEEM is built up (Zeng, 2011; Zeng \& Li, 2013). The present research, through an elaboration of building up an OEEM of LEM in teaching English-Chinese translation supported with contextual parameters, aims at advancing a new approach to enrich researches on translation skills. The study will give a particular emphasis to logic thinking operations of meaning extension from concepts in SL to those in TL with efforts to make the illustration inferentially interpretable and 
descriptively verifiable so as to help learners of translation obtain a know-how and know-why expertise as well.

\section{About Open-Ended Empirical Modules and an OEEM of LME}

Module is a technique term in the field of science and technology. It refers to an independent procedure or set of procedural sentences or unit required to fulfill a function in a large-scale design of system (Knoernschild, 2012). And modularity is an attribute of a complex system that advocates designing structures based on minimizing interdependence between modules and maximizing interdependence within them that can be mixed and matched in order to obtain new configurations without loss of the system's functionality or performance (Baldwin \& Clark, 1997, 2000; Langlois, 1992). It is a process in which a system is divided downward into a number of layer-by-layer multi-attribute modules for the purpose of solving a complex problem. And just as Simon (1962) pointed out, modularity is a "relative" attribute of complex systems, so it can be viewed as an effective mode of changing a complex system into well-manageable modules. This paper attempts to introduce the term "modularity" into teaching translation practice by adopting a large-scale number of typical cases collected from big data corpus and sorting them out into well-defined subcategories [Sub-Cs] in terms of their logic relations. The Sub-Cs will be further integrated into a general category [GC], based on which an OEEM is to be built up. The formula is illustrated as follows:

$\mathrm{OEEM}=$ 【TRQ $(\mathrm{GC}) 】\{\mathrm{X} 1, \mathrm{X} 2, \mathrm{X} 3, \mathrm{X} 4, \mathrm{X} 5, \ldots \mathrm{X}-\mathrm{n}\} \rightarrow \sum \mathrm{X} 1(\mathrm{Sub}-\mathrm{C} 1)\{1 \mathrm{a}, 1 \mathrm{~b}, 1 \mathrm{c}, 1 \mathrm{~d}, 1 \mathrm{e}, \ldots 1-\mathrm{n}\} \rightarrow \sum \mathrm{X} 2$ $\left(\right.$ Sub-C2) $\{2 \mathrm{a}, 2 \mathrm{~b}, 2 \mathrm{c}, 2 \mathrm{~d}, 2 \mathrm{e}, \ldots$ 2-n $\} \rightarrow \sum \mathrm{X} 3\left(\right.$ Sub-C3) $\{3 \mathrm{a}, 3 \mathrm{~b}, 3 \mathrm{c}, 3 \mathrm{~d}, 3 \mathrm{e}, \ldots$ 3-n $\} \rightarrow \sum \mathrm{X} 4$ (Sub-C4) $\{\ldots\}$ (TRQ=Targeted Research Question)

Taking knowledge-based predictable regularity into consideration, the construct of an OEEM requires researchers to make in-depth analysis, comprehensive judgment, empirical generalization and categorization of a large number of typical cases collected from large-scale corpus and big data from SL to TL. In this way, an OEEM is a collection of generalized or categorized description for a particular translation skill or strategy or any language units (including single concepts) based on scientific induction and deduction. For example, by collecting 680 concepts of “活动” (Huodong in Chinese and literally means "activity" in English) and their English translations from the bilingual corpus of 67 Chinese governmental white papers and other corpus-based materials in bilingual texts, Zeng and $\mathrm{Li}$ (2011) constructed a corresponding OEEM integrating four subcategories which include empirical rules such as "Realification", "Delexicalization", "Category downgrading" and "Grammaticalization", and demonstrated the possible ranges of regularity of rendering the Chinese phrase of “活动” into English according to different contexts. The present study, with similar method, will examine the OEEM for LEM. Our research method is a bottom-up induction mode in which the nature of each case will be carefully examined, and then, the concept in SL and its extended concept in TL are qualitatively identified so as to reveal the logic relations between them. Following that, the relevant logic thinking forms incarnated in concrete concepts and the motivations of meaning extension are descriptively demonstrated with contextual parameters that determines the translator's choices of the concepts or propositions. Through our inductive analysis of a large-scale number of cases covering over 150 examples, we build up the OEEM of LME in English-Chinese translation which is illustrated in Figure 1 ( “ $\rightarrow$ " represents extension) 


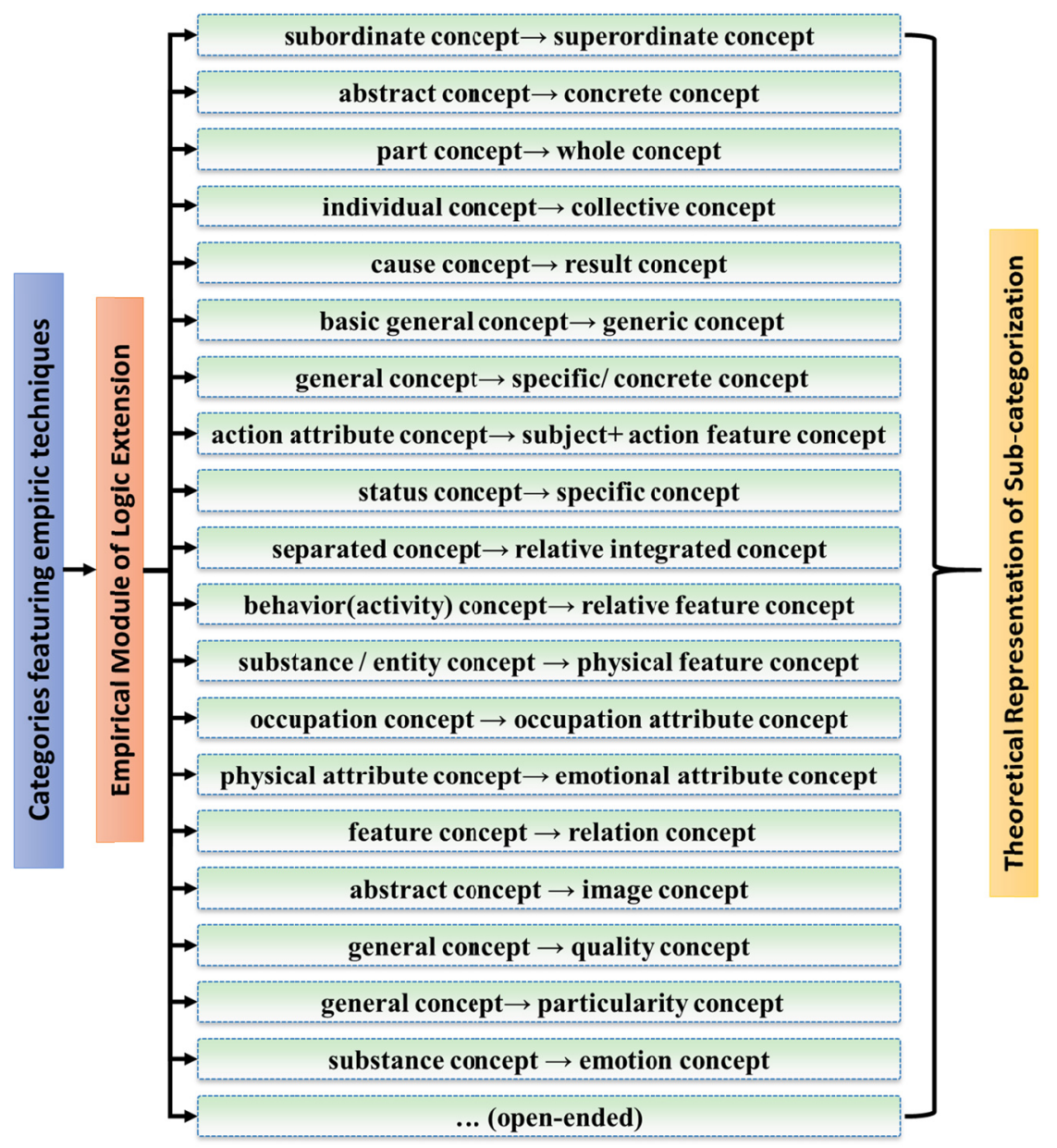

Figure 1. An OEEM of LME showing the range of predictable regularity

The above OEEM greatly enriches the traditional summary of LME for it is enlarged to over twenty subcategories representing manipulatable rules to specify the same skill. It provides the learners of translation with an overall picture of LME and more subcategories can be added to it by other researchers with the same interest from their respective research cases. The categorization of empirical modularity utilizes concrete concepts/terms and is mentally embodied to reveal flexible manipulation of LME in different contexts. In the next section, by adopting the theory of contextual parameters as an analytic tool, we will present the analysis of contextualized LME as an OEEM. Our examples discussed here will come from Xu (2009) who has made an analysis of LEM in English-Chinese translation (E-C translation). In his paper the examples were explained briefly with a few subjective remarks and the underlying mechanism of the intrinsic motivations and the inferential process of logical meaning are not analyzed. The inadequacy of the explanation for LME, to some extent, motives the present study, which aims to demonstrate the inferential process of LME and build up an OEEM for LEM by re-examining the examples.

\section{Demonstrative Analysis of Contextualized LME as an OEEM}

Context has attracted extensive attentions from different disciplines such as literature, semiotics, pragmatics, psycholinguistics, sociolinguistics, etc. (e.g., van Dijk, 1980; Halliday \& Hasan, 1985; Nida, 2001; Xie, 2011) However, traditional definition of "context" is still vague and too general to be able to demonstrate how and why the meaning of a language unit is determined by its context as it is explained by such definitions: "the words that come just before and after a word, phrase or statement and help you to understand its meaning" (Oxford Advanced Learner's Dictionary of Current English, OALD) or "the situation, events, or information that are related to something and that help you to understand it" (Longman Dictionary of Contemporary English) or "the part of a text or statement that surrounds a particular word or passage and determines its meaning" (American Heritage Dictionary). Scholars in the western countries attempt to categorize it into different kinds of contexts as is seen in Malinowski's (1935) classification of linguistic context, situational context and cultural context, or to 
distinguish contextual elements covering social environment, cultural, belief, identity of participants, history and relations seen in Firth (1959) and form, content, background, communicative vehicles, style, goal, tone and interaction seen in Hymes (1972). The Chinese scholars basically follow the same research mode by adding some more kinds or elements to it in their researches (e.g., Wang, 1995; Liu, 2008). But the fact is that simple classification or identification of contextual elements is incapable of solving various complicated problems of construing contextual meanings as it requires manipulative and cognitive computation on conceptual/propositional meaning generalization and transmutation.

With a critical review on relevant discussion on "context" in linguistic and translation studies, and being inspired by Van Dijk's $(2008$, p. 95) idea of "contextual parameters", Zeng $(2011$, p. 7) made a breakthrough by concretizing the traditionally-defined vague notion of context into sets of relevant parameters and defined it as follows:

Context refers to those explicitly and implicitly existing parameters (relevant language units to a target one) in a piece of text/discourse among which there must be a decisive and some auxiliary parameters to be identified that determine or influence reader's meaning construction or project their own semantic features onto the meaning of problem-oriented language units in comprehension and expression" (Zeng, 2011, translation my own).

Zeng (2017, pp. 74-102) did a further systematic study by categorizing contextual parameters into regular and irregular parameters. The former includes topic, theme, intention, subject, object, behavior, method, instrument, result, feature, time, occasion, event, state of affairs, condition, cause-result, species-genus, nature, whole-part, contrast relation, quantity, status, etc.; and the latter includes social or historic events, cultural background, characters' identity and relations and other complicated variables to be qualitatively identified in terms of the contexts in meaning construction. Besides, he illustrated over twenty functions of contextual parameters to demonstrate the operating mechanism of contextualized meaning construction in translation studies such as governance, limitation, mutual relevance, constraint, meaning-projection, extraction, replacement, meaning assignment, meaning extension, meaning convergence, category upgrade and downgrade, specification, exclusiveness, prominence, intensification, etc.

The principle of the inferential operating mechanism of functional contextual parameters in LME is illustrated in the following example:

The bonus is, the show "A Bite of China" is not only about dishes. Every episode will highlight different people, who will tell stories about their adventures with food. (from the documentary "A Bite of China"; words are italicized/ dotted/boldfaced for emphasis by us)

Translation in Chinese: 《舌尖上的中国》不仅展现各种美食，还带给观众额外惊喜。每集都聚焦于不同的 人群，讲述着他们的种种美食奇遇。

The perception of the above contextual parameters identified as decisive and auxiliary ones is realized according to their maximum relevance compared with other words in the context through cognitive inference as discussed in Gutt (1991). The procedural working mechanism of the functional parameters is descriptively demonstrated as follows: 1) "bonus" is a concept indicating substance as defined in the dictionary (bonus: an extra amount of money that is added to a payment, especially to sb's wages as a reward, OALD); 2) Constrained by the topic parameter, decisive and auxiliary parameters, its basic meaning is extended into a contextualized one with its denotative semantic components "money" or "payment (wages)" and "reward" being removed and its connotative components (distinctive feature) "extra" or "additional" being retained to collocate the component(s) given by the decisive parameter through cognitive inference of the reader or translator; 3) The theme of the documentary "A Bite of China" is to present the audience with varieties of delicious food or delicacies across China; here, the sentence says that every episode is not only about dishes but also (contextually implying "extra/additional") about stories by different people who have exciting or unusual experience (relevant semantic components of "adventures") in making wild raw materials into delicious food or delicacies on the table. Therefore, the decisive parameter projects the cognitive meaning "extra pleasure" onto the target concept "bonus"; 4) It is a common knowledge that everyone will have great pleasure for gaining bonus in addition to their regular payment/wages. And when the amount of bonus is big enough, it usually brings surprising pleasure; 5) It can be concluded that the concept “bonus" (奖金/额外津贴) indicating substance is extended to a phrase “extra surprising pleasure" (额外的惊喜) which indicates emotion in this context; 6) Furthermore, we can inductively work out an empirical rule for this subcategory of LME: If a concept indicating substance can bring pleasure to people, it can be extended into concept(s) indicating emotion in a particular context. And the rule reveals its essence or logical basis that the target concept in SL and the extended concept(s) in TL is 
connotatively compatible. For example, bonus (extra/additional) $\rightarrow$ extra surprise (额外津贴/奖金 $\rightarrow$ 额外惊 喜).

Now, with the above exposition of the global view of the topic, we can address to the demonstrative exploration of the context-dependent LME. As mentioned before, we will reexamine the examples by adopting the theory of contextual parameters as an analytic tool. We will first give the subtitles in which the relation of LME is qualitatively inducted and then the reasoning arguments are presented to reveal how an LME is realized with logical motivations.

\subsection{Concept Indicating Physical Entity $\rightarrow$ Concept Indicating State of an Object}

(1) Bloodroot may be rampant in Mr. Darke's neck of the woods, but here it is good dust.

血根草在达克先生居住的森林地区可以长得密密丛丛, 可在我的居处却成了凤毛麟角。(Words are italicized/ dotted/boldfaced for emphasis by us)

In his paper, $\mathrm{Xu}$ (2009) pointed out that gold dust in SL means gold in powdered form so literal translation into Chinese was not proper. Then he stated it was appropriate to explicate its extended meaning "very difficult to obtain and being precious” and the translation “凤毛麟角” (literally “phoenix' feather and unicorn's horn”) was a very good choice. However, Xu's explanation was subjective in the sense that it lacked a clarification of the underlying cognitive mechanism of logic extension. By examining the contextual parameters, we illustrate the inference in a procedural way: 1) "gold dust" is a metaphor with bloodroot being the tenor and gold particles (concept of material or entity) being the vehicle; 2)The similarity between tenor and vehicle can be inferred by empirical knowledge: gold dust is a kind of rare metal powder, and its extension meaning can be rareness and preciousness; 3) Description of the semantic features of the contrastive parameters: rampant (growing too luxuriantly or thickly, OALD) and dust (tiny particles) have the semantic features of 繁茂 (prosperous) and (稀 少)难受 (rare and difficult to find) respectively; the contrastive parameters of place are: Mr. Darke's neck of the woods and here; 4) The reasoning process of LME is descriptively inferred with contextual parameters as follows:

The set of functional contextual parameters $=\sum\{$ contrastive parameter: bloodroot (concept of tenor) + contrastive parameter: gold dust (concept of vehicle) + physical feature parameter: rampant $\} \rightarrow$ gold dust $\rightarrow$ rare to be found (稀少难受 in Chinese) $\rightarrow$ 凤、毛麟角

5)凤毛麟角 is a metonymy and its logic meaning is “difficult/rare to find” (难受; 稀有). Therefore, the contextualized LME is “稀少难受” in Chinese translation; 6) The inferential process shows an empirical rule for specifying the skill: A concept indicating physical entity in SL can be extended to a concept indicating state of an object in TL.

4.2 Concept Indicating Cause of Event $\rightarrow$ Proposition Indicating Result of Event

(2) I've tried, but soil or climate or competition, or all three, eventually took their roll, and it isn't one of our harbingers any more. It is vanished.

我试种过，但由于土壤、气候、植物竞争诸方面或其中一方面的原因，最终没有成功。血根草不再是报 春的使者。它绝迹了。

$\mathrm{Xu}$ argued that the English idiom "took their roll" meant "having a very bad effect on something or somebody over a long period of time". However, he did not make any explanation about the logic inference of meaning extension and offered no empirical rule. Our workable inferring procedure is demonstrated as follows:

1) "take their roll" can be defined as a proposition indicating the cause of an event, and its exact meaning is influenced by various concrete parameters like behavior, object, environment, cause parameters; 2) The proposition “took their roll” is translated into Chinese as “试种没有成功” (the planting trial was not successful) indicates the result of the event concerned; 3) The inferring mechanism guided by contextual parameters is presented as follows:

The set of functional contextual parameters $=\sum$ \{behavior parameter: tried + object parameter: bloodroot + environmental condition parameters: soil, climate, competition + state parameter: vanished $\} \rightarrow$ took their role (cause) $\rightarrow$ (使得) “试种没有成功” (a proposition indicating the result of an event)

4) The empirical rule is inducted as: A proposition indicating the cause of an event in SL can be logically extended to a proposition in TL indicating the result of an event in particular contexts.

\subsection{Basic Category Concept $\rightarrow$ Superordinate Generic Concept}

(3) Insulating protective clothing are gloves, boots, overshoes, protective overalls, headgear. 


\section{绝缘劳保用品包括 (多指) 手套、长靴和胶鞋、防护服和安全帽。}

Xu insisted that the concept of clothing should not be translated as “防护服” because it was not an equivalent of “手套、长靴、胶鞋、防护服和安全帽”. Then, he explained that according to the internal logic of semantic relation, “clothing” could be translated as “用品” (literally “articles for use"). Although the Chinese translation makes sense, his argumentation is not convincing as there is no mention of the reasoning process. We can illustrate the underlying logic and the thinking mechanism as follows: 1) "clothing", a synonym of clothes, is a generic concept referring to articles or items of clothes; and gloves, boots, overshoes, protective overalls, headgear are all subordinate concepts indicating specific categories under clothing. And the two concepts form a generic-species/type relation; 2) to make the relation logically accurate in Chinese translation, the basic category concept clothing is upgraded to a superordinate concept “用品”; 3) The thinking mechanism of the LME under the guidance of contextual parameters is described as follows:

The set of functional contextual parameters $=\sum$ \{subordinate concept parameters (such as gloves, boots, overshoes, protective overalls, headgear) + attribute parameter indicating function (insulating protective) $\} \rightarrow$ clothing (basic category concept) $\rightarrow$ 用品 (superordinate concept) $\}$

4) The empirical rules based on this case can inductively generalized as follows: for LME, a basic category concept in SL can be upgraded to a superordinate concept according to their generic-species/type relation and inversely a basic category concept in SL can be down-graded to a subordinate concept in particular contexts.

\subsection{General Concept $\rightarrow$ Concept Indicating Specific Activity}

(4) Gun directing radar can allow the crew to execute his mission with accuracy.

\section{火炮瞄准雷达可使炮手准确地射击。}

$\mathrm{Xu}$ stated that translating mission as “执行其使命” (literally “carry out one’s mission”) in Chinese was inappropriate as it should be rendered as “射击” (shooting) according to context. The translation is sensible, but he failed to give logical explanation to explore the intrinsic relation tween the two concepts. We can present the LME in the above case as follows: 1) From dictionary definitions, we can identify the relevant semantic components: "mission" refers to (a) particular task or duty undertaken by an individual or a group; (b) such a task performed by an individual or unit of the armed forces (OALD). The italicized part of the above definitions is “(部队个人或单位的) 特别任务” in Chinese; 2) “特别任务” is a rather general concept including special tasks such as investigation, combating, fortification, bridge building, minesweeping, etc. according to our background knowledge; 3) With the tool/instrument parameters "gun" and "radar" identified to specify the content of "mission", we get its contextual meaning of "hitting a target accurately by firing a weapon"; therefore, the extended concept “射击” (firing/shooting) in Chinese translation is logically inferred. The thinking mechanism supported with contextual parameters is described as follows:

The set of functional contextual parameters $=\sum\{$ tool/instrument parameter: gun, radar + subject parameter: crew + action parameter: execute + degree parameter: accuracy $\} \rightarrow$ mission (general concept: particular task/duty) $\rightarrow$ fire / shoot to hit the target (specific activity: firing/shooting to hitting target)

4) we can inductively work out an empirical rule from this inferential process: a general concept in SL can be extended to a specific concept indicating a particular activity in TL with relevant contextual parameters.

\subsection{Concept Indicating Result of Action $\rightarrow$ Proposition Consisting of Actor + Action + Result}

(5) For many families, especially in Tokyo, two incomes are a necessary.

\section{对许多家庭来说，夫妻俩都去上班挣钱是迫不得已的事，在东京尤其如此。}

$\mathrm{Xu}$ asserted that the phrase "two incomes" implied both husband and wife were working and they got two incomes, therefore it was a typical case of logic extension. However, the reasoning of word meaning from background information is not enough for the explanation of logical meaning extension. To make the inferring process being convincing and verifiable, an objective analysis of the cognitive inference under the guidance of contextual parameters is needed: 1) identify the relevant semantic features of "income" from its dictionary definitions: money received over a period of time, esp. as payment of work or as interest on investment (OALD); 2) pinpoint relevant contextual parameters and work out their intrinsic logical relation: (a) "family" is a collective concept and consists of members like parents and children; (b) a family life is normally supported by working members like parents (husband and wife), thus the logical meaning components "support families" (养 家 in Chinese) is highlighted in this context. (c) "necessary" is a condition parameter which suggests that the working members in a family are both obliged to support the family; (d) Tokyo is a place parameter. It is widely acknowledged that the living cost in a big city, especially in an international metropolis like Tokyo, is higher 
than that of small places; 3) Logical inference: Supporting family means finding a job $\rightarrow$ Finding a job means securing a regular income $\rightarrow$ both parents (husband and wife) get jobs, the family is supported with two incomes. 4) The thinking mechanism under the guidance of contextual parameters is described as follows:

The set of functional contextual parameters $=\sum$ \{subject parameter: family (collective concept) + actor parameter (cognitively highlighted by family) : parents (husband and wife) + place parameter: Tokyo + condition parameter: necessary $\} \rightarrow$ two incomes (concepts indicating the result of an action like earning an income) $\rightarrow$ 夫 妻俩都上班挣钱 (the extended meaning in Chinese translation which is a proposition consisting of actor + action + result of the action)

5) The empirical rule is inductively summarized for specifying the skill of LME: in a particular context, concepts indicating the result of an action in SL can be extended to a proposition consisting of actor + action + the result of the action in TL. This rule proves one of the facts that language is usually incomplete in communication in certain context and it is to be replenished or enriched by the reader or translator under the guidance of contextual parameters and in this kind of replenishing process, the ability to make logical inferentiality plays an important role in working out the defaulted structural meaning of a proposition by exercising his or her knowledge-based logical inference.

\subsection{Concepts Indicating Positional/Occupational Action $\rightarrow$ Concepts Indicating Relevant Intentional State}

(6) Lee Kwan Yew contemplates retiring with a hand on the helm.

\section{李光耀打算退位而依然听政。}

$\mathrm{Xu}$ classified the above case into the category of LME but did not justify how to extend the English idiom "with a hand on the helm" to the Chinese translation “依然听政” (literally "still administering state affairs"). By reviewing the case, we find that this is a typical case of logical meaning extension, but we also find that Xu's Chinese translation is not correct in the sense of logic. Analyzing with relevant contextual parameters, we make an inferential demonstration of the inferential process as follows: 1) Firstly, Lee Kwan Yew is identified as subject parameter, from which we can also get a position/occupation parameter (the position of former prime minister of Singapore shows his occupation in the politics field) from social background information; 2) “contemplates retiring” (打算退休 in Chinese) can be viewed as an intention + event parameter; and the idiom "with a hand on a helm" means holding a leading position and it serves as a parameter of occupation/position. Rhetorically, it is a metonymy in which an abstract statement is substituted by a concrete thing as is shown in this case: “steer a ship as helmsman" (掌舵) is used to substitute "administer a country as prime minister" (治理 国家(听政);3) With the constraint of the intention and event parameters of "contemplates retiring", it is against the logic to translate "with a hand on a helm" into Chinese as “依然听政” because after handing over the power, a prime minister becomes a former statesman and will not administer the state affairs. But from experiential logic it is possible for a former prime minister to participate in some of state affairs after retirement with his or her influence; 4) Therefore, the meaning extended here in Chinese translation is “参与政务” (literally "participating in some of government affairs"). The logic thinking mechanism supported by relevant contextual parameters is described as follows:

The set of functional contextual parameters $=\sum$ \{subject parameter: Lee Kwan Yew + (implicit) position/occupation parameter (here referring to prime minister) + intention and event parameters: contemplate retiring $\rightarrow \rightarrow$ "with a hand on a helm" (掌舵 here logically means "administering state affairs for a political position/occupation” (治理国家) $\rightarrow$ extended contextualized meaning in Chinese: 李光耀打算退休后仍然参 与政务

5) The empirical rule with this case can be inductively stated as: Concepts indicating positional/occupational action or activity in SL can be extended to concepts in TL indicating relevant intentional state constrained by contextual parameters.

\section{Conclusion}

In this paper, we focus on solving the question "how to make a translation skill widely-workable and being methodologically and theoretically significant", and by adopting the theory of contextual parameters as the analytic tool, we have reexamined the nature of the cases concerning LME in English-Chinese translation. Through demonstration of the logical inferential process of the typical cases, the study has presented a systematic way of generalization and classification of empirical rules for specifying a manipulatable translation skill. The authors also suggest that the generalization of empirical rules for translation skills should be conducted with cases collected in large-scale corpus and big data and it is open to all researchers, teachers and learners with the same interest since translation is very complex and no single researcher can exhaust all the relevant 
phenomena. In this sense, it provides teachers and learners with a possible method to follow in generalizing empirical rules from their own practice to enrich the translating skills concerned. It is believed that the approach of OEEMs can be applied to researches on any other theory-supported translation skills or methods, which is assured to cast light on teaching and learning translation by providing a range of predictable regularity concerning the same language phenomenon.

\section{Acknowledgment}

The authors wish to thank Pro. Binghua Wang and Pro. Defeng Li for their valuable suggestions.

\section{References}

Armstrong, C. B., \& David, C. P. (2016). Disparate semantic ambiguity effects from semantic processing dynamics rather than qualitative task differences. Language, Cognition and Neuroscience, 31, 940-966. https://doi.org/10.1080/23273798.2016.1171366

Austin, J. L. (1962). How to Do Things with Words. Oxford: Oxford University Press.

Baker, M. (1992). In Other Words: A Coursebook on Translation. London and New York, NY: Routledge. https://doi.org/10.4324/9780203133590

Baldwin, Y. C., \& Kim, B. C. (1997). Managing in an age of modularity. Harvard Business Review, 75, 84-93.

Baldwin, Y. C., \& Kim, B. C. (2000). Design Rules (Volume 1: The Power of Modularity). Cambridge, MA: MIT Press. https://doi.org/10.7551/mitpress/2366.001.0001

Bolger, J. D., Balass, M., Landen, E., \& Perfetti, C. A. (2008). Context variation and definitions in learning the meanings of words: An instance-based learning approach. Discourse Process, 45(2), 122-159. https://doi.org/10.1080/01638530701792826

Borghesani, V., Buiatti, M., Eger, E., \& Piazza, M. (2019). Conceptual and Perceptual Dimensions of Word Meaning Are Recovered Rapidly and in Parallel during Reading. Journal of Cognitive Neuroscience, 31(1), 95-108. https://doi.org/10.1162/jocn_a_01328

Butler, Y. G. (2020). The ability of young learners to construct word meaning in context. Studies in Second Language Learning and Teaching, 10(3), 547-578. https://doi.org/10.14746/ssllt.2020.10.3.7

Calvo, E. (2011). Translation and/or translator skills as organising principles for curriculum development practice. The Journal of Specialised Translation, 16, 5-25.

Chandler, D. A. (1995). Texts and the construction of meaning. In D. C. Alfred (Ed.), The Act of Writing (pp. 4-7). Aberystwyth, Great Britain: The University of Wales Press.

Chang, Y.-H., Liu, T.-C., \& Pass, F. (2018). Cognitive resources allocation in computer-mediated dictionary assisted learning: From word meaning to inferential comprehension. Computers \& Education, 127, 113-129. https://doi.org/10.1016/j.compedu.2018.08.013

Chen, T., Koda, K., \& Wiener, S. (2020). Word-meaning inference in L2 Chinese: An interactive effect of learners' linguistic knowledge and words' semantic transparency. Reading and Writing, 33(10), 2639-2660. https://doi.org/10.1007/s11145-020-10058-w

Clark, H. H., \& Richard, J. G. (1983). Understanding old words with new meanings. Journal of Verbal Learning and Verbal Behavior, 22, 591-608. https://doi.org/10.1016/S0022-5371(83)90364-X

Duc, D. N. (2005). Introduction to Formal Logic. Ho Chi Minh: Vietnam National University-HCMC Press.

Duffy, A. S., Morris, R. K., \& Rayner, K. (1988). Lexical ambiguity and fixation times in reading. Journal of Memory and Language, 27, 429-446. https://doi.org/10.1016/0749-596X(88)90066-6

Fang, M. Z. (2017). Subdivision of text types for translation training and translation strategies: The areas of pragmatic translation studies to be exploited II . Shanghai Journal of Translators, 3, 3-8, 93.

Fawcett, P. (2007). Translation and Language: Linguistic Theories Explained. Beijing: Foreign Language Teaching and Research Press.

Firth, J. R. (1959). The Treatment of Language in General Linguistics. London: The Medial Press.

Galántai, D. (2002). Literal meaning in translation. Perspectives, 10(3), 167-192. https://doi.org/10.1080/0907676X.2002.9961443

Grace, A. C. (1998). Retention of word meanings inferred from context and sentence-level translations: Implications for the design of beginning-level CALL software. Modern Language Journal, 82(4), 533-544. 
https://doi.org/10.1111/j.1540-4781.1998.tb05541.x

Gutt, E. A. (1991). Translation and Relevance: Cognition and Context. Manchester: St. Jerome Publishing.

Halliday, M. A. K., \& Ruqaiya, H. (1985). Language, Context and Text: Aspects of Language in a Social Semiotic Perspective. Victoria: Deakin University.

Hymes, D. (1972). On Communicative Competence. In J. B. Pride \& H. James (Eds.), Sociolinguistics. Harmondsworth: Penguin.

Jakobsen, A. L. (1993). Translation as textual (re)production. Perspectives: Studies in Translatology, 2, 155-165. https://doi.org/10.1080/0907676X.1993.9961209

Jurko, P. (2017). Pragmatic meaning in contrast: Semantic prosodies of Slovene and English. Perspectives, 25(1), 157-176. https://doi.org/10.1080/0907676X.2016.1165262

Kanasugi, P. (2019). Parts of speech membership as a factor of meaning extension and level of abstraction. Review of Cognitive Linguistics, 17(1), 78-112. https://doi.org/10.1075/rcl.00027.kan

Ke, S., \& Keiko, K. (2019). Is Vocabulary Knowledge Sufficient for Word-Meaning Inference? An Investigation of the Role of Morphological Awareness in Adult L2 Learners of Chinese. Applied Linguistics, 40(3), 456-477. https://doi.org/10.1093/applin/amx040

Knoernschild, K. (2012). Java Application Architecture: Modularity Patterns with Examples Using OSGi. Upper Saddle River, NJ: Prentice Hall.

Langacker, W. R. (2000). Grammar and conceptualization. Berlin: Mouton de Gruyter. https://doi.org/10.1515/9783110800524

Langlois, N. R. (1992). External economies and economic progress: The case of the microcomputer industry. Business History Review, 66, 1-50. https://doi.org/10.2307/3117052

Liu, H. Z. (2008). Contextual Meanings in Translation. Journal of Hubei University of Economics, 5, 127-129.

Malinowski, B. K. (1935). Coral Gardens and Their Magic. London: Routledge.

Nida, A. E. (2001). Contexts in Translating. Amsterdam/Philadelphia: John Benjamins Publishing Company. https://doi.org/10.1075/btl.41

Nord, C. (1991). Text analysis in translation: Theory, methodology, and didactic application of a model for translation-oriented text analysis. Amsterdam: Rodopi.

PACTE. (2003). Building a Translation Competence Model. In F. Alves (Ed.), Triangulating Translation: Perspectives in Process Oriented Research (pp. 43-66). Philadelphia/Amsterdam: John Benjamins. https://doi.org/10.1075/btl.45.06pac

PACTE. (2015). Results of PACTE's Experimental Research on the Acquisition of Translation Competence: The Acquisition of Declarative and Procedural Knowledge in Translation. The Dynamic Translation Index. Translation Spaces, 4(1), 29-53. https://doi.org/10.1075/ts.4.1.02bee

Rodd, M. J. (2020). Settling into Semantic Space: An Ambiguity-Focused Account of Word-Meaning Access. Perspectives on Psychological Science, 15(2), 411-427. https://doi.org/10.1177/1745691619885860

Simon, A. H. (1962). The architecture of complexity. Proceedings of the American Philosophical Society, 106, 467-482.

Smith, P. (2003). An Introduction to Formal Logic. Cambridge: Cambridge University Press.

Vahid, D. H., \& Elahe, M. S. (2011). Word Choice and Symbolic Language: A Case Study of Persian Translations of THE SCARLET LETTER. International Journal of English Linguistics, 1(2), 186-195. https://doi.org/10.5539/ijel.v1n2p186

van Dijk, A. T. (2008). Discourse and Context: A Socio-cognitive Approach. Cambridge: Cambridge University Press. https://doi.org/10.1017/CBO9780511481499

Vitello, S., \& Jennifer, M. R. (2015). Resolving semantic ambiguities in sentences: Cognitive processes and brain mechanisms. Linguistics and Language Compass, 9, 391-405. https://doi.org/10.1111/lnc3.12160

Wang, B. Q. (1995). Cultural Translation Studies. Tianjin: Nankai University Press.

Xie, M. (2011). Contexts in poetic translation: iterability, event, openness. Perspectives, 19(3), 205-219. https://doi.org/10.1080/0907676X.2010.514349 
Xu, C. H. (2009). Word Meaning Extension in English-Chinese Translation. Chinese Science and Technology Translators Journal, 2, 10-13.

Yeibo, E. (2011). Patterns of Lexical Choices and Stylistic Function in J. P. Clark-Bekederemo's Poetry. International Journal of English Linguistics, 1(1), 137-149. https://doi.org/10.5539/ijel.v1n1p137

Zeng, L. S. (2002). On 'Operation Visions' and 'Parameter Factors'. Modern Languages, 2, 154-164, 153.

Zeng, L. S. (2011). Cognitive mechanism of concept meaning based on theory of contextual parameters. Foreign Language Teaching, 6, 5-9.

Zeng, L. S. (2012a). Multidimensional exploration of theories of Translatology. Shanghai: Shanghai Foreign Language Education Press.

Zeng, L. S. (2012b). On logic foundation of integrating and expanding category system of pragmatic Translatology. Shanghai Journal of Translators, 4, 1-6.

Zeng, L. S. (2013). On methodological development of theoretic logical categories of pragmatic Translatology. Shanghai Journal of Translators, 3, 2-7.

Zeng, L. S. (2017). An Innovative Approach to Researches on Translation of Business Texts. Beijing: Foreign Language Teaching and Research Press.

Zeng, L. S., \& Yanna, L. (2011). On explicit and implicit English manifestations of Chinese category concept Huodong from the theory of contextual parameters: Developing empirical and theoretical modules in pragmatic Translatology. Shanghai Journal of Translators, 2, 1-6.

\section{Copyrights}

Copyright for this article is retained by the author, with first publication rights granted to the journal.

This is an open-access article distributed under the terms and conditions of the Creative Commons Attribution license (http://creativecommons.org/licenses/by/4.0/). 